\title{
A IMUNIDADE DOS NACIONAIS AMERICANOS À JURISDIÇÃO DO TRIBUNAL PENAL INTERNACIONAL
}

Isabela Piacentini de Andrade e Fernanda Araújo Kallas ${ }^{1}$

\section{RESUMO}

A jurisdição do Tribunal Penal Internacional pode exercer-se não somente sobre nacionais de Estados Partes do Estatuto de Roma, mas também sobre nacionais de Estados não Partes, caso eles sejam acusados de ter cometido um dos crimes de competência do Tribunal dentro do território de um Estado Parte. O temor dos Estados Unidos, Estado não Parte do Estatuto, de ter seus nacionais processados pelo Tribunal nesta hipótese motivou ações americanas visando a evitar que isso ocorra. A busca da imunidade para os cidadãos americanos começou pela solicitação ao Conselho de Segurança de Resoluções impedindo que 0 Tribunal pudesse iniciar inquérito ou procedimento criminal contra o pessoal de um Estado não Parte atuando em forças da ONU. Em seguida, os Estados Unidos passaram a celebrar inúmeros acordos bilaterais com Estados Partes e não Partes ao Estatuto pelos quais estes se comprometem a não entregar nacionais americanos para o Tribunal Penal Internacional.

\section{ABSTRACT}

The jurisdiction of the International Criminal Court can be exercised not only over nationals of State Parties to the Rome Statute, but also over nationals of non-State Parties if such nationals are accused of having committed a crime falling within the jurisdiction of the Court on the territory of a State Party. Fearing of having their nationals being prosecuted by the Court, the United States, a non-State party, has taken measures in order to prevent that from happening. The search for immunity of their nationals began with a request to

Mestrandas em Direito Internacional Público pela Universidade de Paris II.

Revista Brasileira de Direito Internacional, Curitiba, v.1, n.1, jan./jun.2005 
the Security Council for a Resolution that prevents the Court from investigating or prosecuting the personnel of a non-State Party contributing to a United Nations operation. Furthermore, the US commenced to conclude several bilateral agreements, with State Parties and non-State Parties, according to which they would not surrender an American citizen to the International Criminal Court.

\section{INTRODUÇÃO}

Amplamente divulgado, o escândalo das torturas cometidas por soldados americanos na prisão iraquiana de Abou $\mathrm{Ghraib}^{2}$ desperta interrogações sobre sua responsabilidade diante da justiça criminal internacional.

Segundo relatos dos prisioneiros iraquianos e dos próprios soldados, além de alguns relatórios produzidos pelo governo americano (Taguba e Schesinger), pela Cruz Vermelha, Human Rights Watch e Anistia Internacional, os métodos adotados durante os interrogatórios conduzidos pelos militares americanos contra os detentos revelam inúmeras crueldades: privação de sono durante longos períodos, submissão a temperaturas extremas de frio e calor, privação de comida e de água, manutenção de prisioneiros totalmente nus em células vazias na escuridão total durante vários dias, coação a ficar em posições penosas e desconfortáveis, derramamento de substâncias químicas sobre a pele e os olhos dos prisioneiros, torturas ou violências com objetos duros levando às vezes à morte, derramamento de água fria sobre prisioneiros nus, e humilhações de caráter sexual, como obrigar os iraquianos a simular relações sexuais, a se masturbar ou utilizar lingerie feminina, e fazer pirâmides humanas de prisioneiros nus.

Esses tratamentos, que segundo investigações fariam parte de um vasto esquema coordenado por membros da inteligência militar americana, representam sem dúvida uma violação à Convenção contra a Tortura e outras

\footnotetext{
2 Ver por exemplo o dossiê "La torture dans la guerre", publicado pelo jornal Le Monde na edição de 9-10 de maio de 2004.
}

Revista Brasileira de Direito Internacional, Curitiba, v.1, n.1, jan./jun.2005 
Penas ou Tratamentos Cruéis, Desumanos ou Degradantes de 1984 e às Convenções de Genebra de 1949 sobre o direito internacional humanitário.

Tais práticas poderiam ser igualmente consideradas como crimes de guerra segundo 0 artigo $8^{\circ}$ do Estatuto de Roma $^{3}$ do Tribunal Penal Internacional (TPI), o qual condena as violações graves às Convenções de Genebra tais como a tortura ou outros tratamentos desumanos (art. 8, a), ii), o ato de causar intencionalmente grande sofrimento ou ofensas graves à integridade física ou à saúde (art. 8, a), iii), assim como outras violações graves das leis e costumes aplicáveis em conflitos armados no âmbito do direito internacional tais como o ultraje à dignidade da pessoa, em particular por meio de tratamentos humilhantes e degradantes (art. 8, b), xxi) e a prática de atos de violência sexual (art. 8, b), xxii).

A rejeição americana a submeter seus nacionais a uma justiça penal internacional capaz de condenar crimes deste tipo é bem conhecida. Desde a criação do Tribunal Penal Internacional, os americanos têm se mostrado contrários à nova jurisdição. Opositor contumaz durante a Conferência de Plenipotenciários que culminou na adoção do Estatuto de Roma, os Estados Unidos decepcionaram a comunidade internacional ao retirar, em 6 de maio de 2002, sua assinatura do Estatuto ${ }^{4}$. Entretanto, julgando que não fazer parte do TPI não seria suficiente para satisfazer seus interesses, eles iniciam em seguida uma verdadeira campanha contra o Tribunal em busca de garantir a imunidade de seus nacionais.

\footnotetext{
$3 \quad$ Promulgado pelo Decreto 4.388, de 25 de setembro de 2002.

4 Os EUA, após grandes hesitações, assinaram o Estatuto de Roma em 31 de dezembro de 2000, data limite prevista pelo artigo 127 (1).
}

Revista Brasileira de Direito Internacional, Curitiba, v.1, n.1, jan./jun.2005 


\section{O EXERCÍCIO DA JURISDIÇÃO DO TRIBUNAL PENAL INTERNACIONAL}

Em regra, o Estatuto do TPI não pode ser aplicado a países que não aderiram a ele. Entretanto, é possível que o nacional de um Estado não Parte seja sujeito à jurisdição do Tribunal se ele comete um crime de competência do Tribunal (art. $5^{\circ}$.) no território de um Estado que é Parte (art. 12 (2), a). O exercício da jurisdição da Corte Criminal pode basear-se portanto em dois critérios, segundo o artigo 12: a nacionalidade e a territorialidade. Segundo a primeira hipótese, o TPI poderia exercer sua jurisdição sobre um acusado se o Estado do qual ele é nacional é Parte no Estatuto. O segundo critério estende a jurisdição da Corte sobre o território de um Estado Parte: o TPI poderia processar nacionais de Estados não Partes se estes cometeram um crime no território de um Estado Parte.

Assim, a despeito da não participação dos EUA no TPI, é possível que cidadãos americanos sejam chamados a responder diante do Tribunal caso sejam acusados de ter cometido algum dos crimes previstos pelo artigo $5^{\circ}$. do Estatuto no território de um Estado Parte.

Para tanto, será necessário entregar o indivíduo ao TPI, obrigação esta que cabe aos Estados Partes sob a base da cooperação, já que o TPI não dispõe de meios coercitivos para fazê-lo. $O$ artigo 86 do Estatuto prevê que todos os Estados Partes têm a obrigação de cooperar plenamente com 0 Tribunal no inquérito e no procedimento contra crimes de competência da Corte Criminal. A detenção e a entrega para o TPI sob sua solicitação de pessoas que se encontrem no território de um Estado Parte é uma das formas desta cooperação obrigatória, prevista pelo artigo 89. $\mathrm{O}$ fato do Estado requerido não ser Parte ao Estatuto não exclui a possibilidade de que ele possa cooperar, conforme previsão do artigo 87.

Tendo em vista a jurisdição "expansiva" do Tribunal fundada sobre a territorialidade e considerando a grande participação das forças militares americanas nas operações de manutenção da paz internacionais e nas missões de caráter humanitário da ONU, os Estados Unidos ficaram temerosos 
que os Estados Partes procedessem a entrega de soldados americanos ao Tribunal Penal Internacional se estes fossem acusados da prática de um dos crimes previstos no Estatuto de Roma. Sendo assim, os EUA resolveram condicionar seu apoio a novas operações de manutenção da paz das Nações Unidas à adoção pelo Conselho de Segurança de uma Resolução imunizando nacionais de países não partes ao Estatuto de Roma que atuem em forças da ONU.

Revista Brasileira de Direito Internacional, Curitiba, v.1, n.1, jan./jun.2005 


\section{RESOLUÇÕES DO CONSELHO DE SEGURANÇA CONCEDENDO IMUNIDADE À JURISDIÇÃO DO TPI}

Foi adotada, por estas razões, em 12 de julho de 2002 - apenas onze dias após a entrada em vigor do Estatuto do Tribunal Penal Internacional -, a Resolução 1422 pelo Conselho de Segurança, prevendo que, durante o período de um ano, situações envolvendo o pessoal de um Estado não Parte do Estatuto atuando em operações da ONU não poderiam ser objeto de inquérito ou procedimento criminal do TPI, salvo decisão contrária do Conselho.

Tal resolução foi alvo de várias críticas. Muitos a consideraram incompatível com o Estatuto, pois se um nacional de um Estado Parte atuasse sob o comando de um Estado não Parte, ele se beneficiaria também da imunidade segundo o texto da Resolução. Outros enxergam na Resolução uma violação do artigo 16 do Tratado de Roma, o qual permite que o Conselho impeça o inquérito ou o início de procedimentos criminais pelo TPI contra uma pessoa, mas somente caso a caso e não de forma ilimitada e sistemática como prevê a Resolução (para todo o pessoal de um Estado não Parte contribuindo numa operação da $\mathrm{ONU}$ ). $\mathrm{O}$ fato de a Resolução limitar-se ao período de um ano não afastaria a ilegalidade. ${ }^{5}$

A despeito das críticas, a imunidade foi prorrogada por mais um ano através da Resolução 1487 de 12 de junho de 2003. A exceção foi igualmente prevista para o pessoal destinado a atuar na força multinacional na Libéria, através da Resolução 1497 de $1^{\circ}$. de agosto de 2003.

Em 2004, os Estados Unidos intentaram uma nova renovação desse "status" de imunidade. Entretanto, a proposta americana foi abandonada devido à baixa probabilidade de sua aprovação pelo Conselho de Segurança; o Brasil foi um dos sete países que mostrou-se contrário à nova Resolução ${ }^{6}$.

\footnotetext{
$5 \quad$ Para uma análise aprofundada ver DENIS, Catherine. Le pouvoir normatif du Conseil de sécurité des Nations Unies: portée et limites. Bruxelles: Bruylant, 2004, p. 124 e ss.

Os sete países que anunciaram suas intenções de se abster de votar, tornando impossível a obtenção do número de votos necessários para a aprovação da Resolução foram: Brasil, Espanha, França, Alemanha, Benim, Chile e China. Para maiores detalhes sobre a polêmica em torno da renovação da Resolução, ver PASTUJOVA, Kerstin. Was the United
}

Revista Brasileira de Direito Internacional, Curitiba, v.1, n.1, jan./jun.2005 
Aparentemente, o repúdio à renovação da imunidade decorreu grandemente da revelação do escândalo de Abou Ghraib. ${ }^{7}$ Diante do seu insucesso, os Estados Unidos reforçam uma outra vertente da estratégia por eles adotada para evitar a jurisdição da Corte Penal: a celebração de acordos bilaterais de imunidade. ${ }^{8}$

States justified in renewing Resolution 1487 in light of the Abu Ghraib prisoner abuse scandal?, ILSA Journal of International and Comparative Law, vol. 11, p. 195-216, 2004.

BENZING, Marcus. U.S. Bilateral Non-Surrender Agreements and Article 98 of the Statute of the International Criminal Court: An Exercise in the Law of Treaties. Max Planck Yearbook of United Nations Law, vol. 8, 2004, p. 188 e PASTUJOVA, op. cit. nota supra.

É importante lembrar que todos esses esforços americanos foram feitos para cobrir uma brecha que permitiria o julgamento de seus nacionais se duas situações se conjugassem: um crime de competência do TPI fosse cometido por um nacional americano no território de um Estado Parte, e a ausência ou incapacidade de julgamento do crime por este Estado ou pelos Estados Unidos. Não se deve esquecer que a jurisdição do TPI é apenas subsidiária às jurisdições internas. A hipótese parece excepcional, entretanto não é inconcebível, bastando para isso notar a existência de tribunais penais internacionais ad hoc.

Revista Brasileira de Direito Internacional, Curitiba, v.1, n.1, jan./jun.2005 


\section{ACORDOS BILATERAIS DE IMUNIDADE}

\subsection{CARACTERÍSTICAS GERAIS}

Insatisfeitos, os Estados Unidos decidiram também fazer pressão sobre os Estados na tentativa de permitir aos seus nacionais de escapar completamente da jurisdição criminal internacional. Assim, eles passaram a celebrar acordos bilaterais segundo os quais os nacionais americanos ficariam imunes à jurisdição do TPI.

Estes acordos baseiam-se nas condições previstas pelo artigo 98 (2) do Estatuto de Roma, que dispõe:

\footnotetext{
"O Tribunal não pode dar seguimento à execução de um pedido de entrega por força do qual o Estado requerido devesse atuar de forma incompatível com as obrigações que lhe incumbem em virtude de acordos internacionais à luz dos quais o consentimento do Estado de envio é necessário para que uma pessoa pertencente a esse Estado seja entregue ao Tribunal, a menos que o Tribunal consiga, previamente, obter a cooperação do Estado de envio para consentir na entrega."
}

Visando a tirar proveito da exceção que prevê o artigo, os EUA criaram acordos bilaterais de três diferentes tipos. O primeiro, baseado na reciprocidade, prevê que cada Estado se compromete a não entregar os nacionais do outro Estado ao TPI sem o consentimento expresso da outra parte. Um segundo modelo de acordo prevê apenas a obrigação para um Estado Parte do TPI de não entregar nacionais americanos para a Corte sem o consentimento dos Estados Unidos. E uma terceira espécie, destinada a Estados que não assinaram nem ratificaram o Estatuto de Roma, prevê que as partes não devem deliberamente facilitar, consentir ou cooperar com tentativas de terceiros de entregar um nacional da outra parte à Corte. ${ }^{9}$

\footnotetext{
9 BOUQUEMONT, Clémence. La Cour pénale internationale et les États-Unis. Paris: L'Harmattan, 2003, p. 111-112.
}

Revista Brasileira de Direito Internacional, Curitiba, v.1, n.1, jan./jun.2005 
Até 14 de abril de 2006, o número de acordos assinados segundo o U.S. State Departement seria de 100, sendo que 43 teriam sido assinados por Estados Partes do Estatuto de Roma. ${ }^{10}$

A conseqüência da proliferação desses tratados bilaterais não é somente um aumento do número de cidadãos americanos imunes perante a Corte, mas também de cidadãos de outras nacionalidades se o tratado prevê obrigações recíprocas. A quantidade de pessoas de nacionalidades diversas que poderiam escapar à jurisdição do TPI aumentaria, pois, a cada tratado concluído com os Estados Unidos, podendo crescer ainda mais se, além dos tratados celebrados com os americanos, outros Estados resolverem concluir entre si tais acordos. A propagação de tal prática teria conseqüências nefastas para o futuro do TPI, na medida em que reduziria a possibilidade do exercício de sua jurisdição sobre criminosos potenciais.

A pressão americana para que os Estados assinem os acordos bilaterais é feita através de meios políticos e financeiros, como por exemplo a supressão de ajuda militar fornecida pelos Estados Unidos. Observa-se então, por razões óbvias, que a totalidade dos países que cederam às pressões americanas assinando acordos bilaterais são subdesenvolvidos.

Não obstante, a maioria dos Estados Partes ao Estatuto do TPI resistiram a essas pressões e 54 países recusam publicamente a assinatura desses acordos. O Brasil está entre este número, e o custo da recusa foi a perda de uma ajuda de 500.000 dólares em 2004. Para outros países da América do Sul, como o Peru, o Equador e o Uruguai, o impacto foi mais significativo. ${ }^{11}$ Tais conseqüências não assustaram os membros do Mercosul, que em 20 de junho de 2005 adotaram a posição comum de não concluir nenhum tipo de acordo multilateral ou bilateral que possa afetar a jurisdição do

\footnotetext{
10 Status of US Bilateral Immunity Agreements (BIAs), documento disponível no site www.iccnow.org. Acesso em 24 de maio de 2006.

Countries Opposed to Signing a US Bilateral Immunity Agreement (BIA): US Aid Lost in FY04 and US Aid Threatened in FY05, documento disponível no site www.iccnow.org. Acesso em 24 de maio de 2006.
}

Revista Brasileira de Direito Internacional, Curitiba, v.1, n.1, jan./jun.2005 
Tribunal Penal Internacional ou outras das obrigações estabelecidas no Tratado de Roma. ${ }^{12}$

\subsection{LEGALIDADE}

A legalidade dos acordos bilaterais de imunidade é contestada por alguns juristas, além de ONGs engajadas na luta contra tais instrumentos, que foram apelidados de "acordos de impunidade". ${ }^{13}$

A questão da legalidade dos acordos não se coloca para os Estados Unidos, já que eles não são Partes no Estatuto, e sim aos Estados Partes, que são obrigados pelo princípio do pacta sunt servanda a se conformar às suas previsões.

A análise da legalidade é indispensável para saber se os acordos são capazes de produzir os efeitos intentados pelos Estados Unidos, ou seja, impedir o TPI de obter a entrega de nacionais, enquadrando os acordos na hipótese prevista pelo artigo 98 (2) do Estatuto.

O artigo 98 (2) seria uma exceção ao dever de cooperar plenamente com ○ Tribunal (art. 86), o que inclui a obrigação para ○ Estado Parte de entregar pessoas ao TPI se este o solicitar (art. 89). A razão de ser do artigo 98 (2) é a proteção de obrigações internacionais assumidas por um Estado Parte perante terceiros Estados que seriam conflitantes com a obrigação de entregar prevista pelo Estatuto. A disposição evita, assim, que o Estado Parte seja responsável internacionalmente pelo desrespeito de obrigações convencionais. ${ }^{14}$

Essa preocupação de respeitar obrigações contraídas internacionalmente, motivo da existência do artigo 98 (2), teria sido discutida durante as negociações do Estatuto em 1998 tendo-se em mente somente os tratados concluídos antes da entrada em vigor do Estatuto. Assim, uma

\footnotetext{
12 Declaración Presidencial sobre Compromiso del Mercosur con el Estatuto de Roma de la Corte Penal Internacional, 20 de junho de 2005, disponível no site www.mercosur.int.

${ }_{13}$ EUBANY, Cosmos. Justice for Some? U.S. Efforts Under Article 98 to Escape the Jurisdiction of the International Criminal Court. Hastings International and Comparative Law Review, vol. 27, n. 1, 2003, p. 124.

14 BENZING, p. 198.
}

Revista Brasileira de Direito Internacional, Curitiba, v.1, n.1, jan./jun.2005 
interpretação do artigo levando-se em consideração seu contexto de criação só admitiria a exceção de não entregar no caso de acordos celebrados anteriormente. A utilização americana deste artigo seria portanto sinal de uma interpretação abusiva, pois acordos posteriores à entrada em vigor do Estatuto não poderiam se beneficiar das disposições do artigo. ${ }^{15}$

A interpretação acima, baseada na intenção dos criadores do tratado manifestada nos trabalhos preparatórios, não é entretanto a única admissível. Segundo a Convenção de Viena sobre o Direito dos Tratados de $1969^{16}$, a utlização dos trabalhos preparatórios e circunstâncias nas quais o tratado foi concluído é um método subsidiário de interpretação, que deve ser utilizado caso uma interpretação conduza a um resultado manifestamente absurdo ou não razoável (art. 32). A regra primeira de interpretação de tratados contida na Convenção está no artigo 31, e estabelece que um tratado deve ser interpretado de boa fé e à luz de seu objeto e finalidade. Ora, o objetivo do Estatuto de Roma é o de promover a punição dos responsáveis pelos crimes mais graves à humanidade. A conclusão de acordos impedindo o exercício da jurisdição da Corte seria portanto uma atitude contrária ao objeto e finalidade do Estatuto de Roma. ${ }^{17}$ Esta incongruência também seria condenada pelo artigo 18 da Convenção de Viena, segundo o qual as partes devem se abster de todo ato que prive um tratado de seu objeto e fim.

A interpretação americana seria portanto contrária ao espírito do Estatuto e os Estados Partes que concluem tais acordos bilaterais estariam violando este instrumento.

Segundo o artigo 119 (1) do Estatuto, cabe ao próprio Tribunal decidir sobre diferendos relativos às suas funções judiciais. Assim, admitindo-se a hipótese de que o TPI, exercendo tais funções, resolva solicitar a entrega de um nacional americano a um Estado Parte que tenha se comprometido por um acordo bilateral a não fazê-lo, tal Estado não poderá se opor baseando-se na

15 CLAIRE, Trean. Une interprétation abusive de l'article 98 du traité de Rome, Le Monde, 4.09.2002, p. 02.

${ }_{16} \quad$ Embora não seja objeto de adesão massiva dos Estados, esta Convenção seria ainda assim amplamente aplicável segundo a doutrina pois seria expressão do costume internacional sobre a matéria.

BOUQUEMONT, op. cit., p. 118.

Revista Brasileira de Direito Internacional, Curitiba, v.1, n.1, jan./jun.2005 
interpretação americana do artigo 98 (2); a estratégia dos EUA seria portanto ineficaz se o TPI interpretar o artigo 98 (2) segundo os critérios da Convenção de Viena assinalados acima, segundo os quais (a) os acordos bilaterais seriam contrários ao espírito do Estatuto, e (b) não poderiam se beneficiar do artigo 98 (2) se concluídos posteriormente à sua entrada em vigor.

Assim, como bem lembra BENZING, um Estado Parte não teria a faculdade de se recusar a cooperar com o Tribunal baseando-se na sua própria interpretação do Estatuto, já que caberia ao TPI na qualidade de corte internacional a competência para interpretar as disposições de seu tratado constitutivo. $^{18}$

No advento de um pedido de entrega de um indivíduo ao TPI, o Estado Parte que celebrou um acordo bilateral estaria portanto diante de um dilema, e sua escolha não é isenta de conseqüências. Se ele decide não entregar o indivíduo ao TPI, ele viola o Estatuto de Roma, e incorre em responsabilidade internacional perante o TPI e os demais Estados Partes. Além disso, a recusa pode motivar o Tribunal a elaborar um relatório e submeter a questão à Assembléia dos Estados Partes ou ao Conselho de Segurança (art. 87 (7)). Caso ele decida entregar o indivíduo, ele infringe a obrigação assumida pelo tratado bilateral, e será responsável por esta violação perante os Estados Unidos segundo as disposições do tratado e as normas de responsabilidade internacional dos Estados. ${ }^{19}$ Vale lembrar entretanto que não há violação do Estatuto na primeira hipótese (recusa a entregar) se o acordo bilateral foi assinado entre dois países não Partes no Estatuto de Roma.

A questão da legalidade dos acordos bilaterais permanece entretanto ainda meramente teórica, já que o TPI ainda não se deparou com nenhuma situação fática que pudesse ensejar o pedido de entrega de um nacional americano que tenha cometido um dos crimes previstos pelo artigo $5^{\circ}$. no território de um Estado Parte. Os abusos cometidos em Abou Ghraib, se por um lado se enquadrariam como crimes de guerra segundo 0 artigo $8^{\circ}$. do Estatuto, por outro lado não poderiam ser alcançados pela jurisdição do TPI

18 BENZING, op. cit., p. 199-200.
$19 \quad$ BENZING, op. cit., p. 231.

Revista Brasileira de Direito Internacional, Curitiba, v.1, n.1, jan./jun.2005 
pois não foram cometidos no território de um Estado Parte, já que o Iraque não é Parte no Estatuto de Roma.

$\mathrm{Na}$ ausência de uma aplicação prática dos acordos bilaterais, portanto, a dúvida sobre sua legalidade fica em suspenso, e o risco que eles representam à eficácia do TPI permanece.

Revista Brasileira de Direito Internacional, Curitiba, v.1, n.1, jan./jun.2005 


\section{CONCLUSÃO}

O temor americano diante da jurisdição do Tribunal é justificável. O corpo militar americano está espalhado em diversos pontos do globo servindo ora a propósitos da $\mathrm{ONU}$, ora a propósitos próprios. Não é à toa que os Estados Unidos ganharam o qualificativo de "polícia mundial". Os exemplos do unilateralismo americano abundam, e a sujeição de seus nacionais a uma jurisdição criminal internacional não se coadunam com sua estratégia de dominar sem serem controlados. Os abusos de Abou Ghraib são um claro exemplo do exercício do poder militar americano de forma unilateral e sem um efetivo controle internacional. Vários são os sinais de que a tortura em Abou Ghraib não foi um mero deslize funcional de alguns soldados, mas que contava com apoio institucional e fazia parte de um esquema previamente concebido. As suspeitas de violação de direitos e de tortura contra supostos "terroristas" detentos na base americana de Guantánamo em Cuba, batizado de território "sem lei", reforçam a hipótese de que os Estados Unidos querem ter a plena liberdade de agir unicamente segundo Ihes convêm, ignorando qualquer controle ou norma internacional que contrarie seus propósitos.

Envolvidos em guerras ocorrendo em diversas partes do globo, os nacionais americanos, inclusive aqueles de alto escalão eventualmente executando uma estratégia oficial, encontrariam um freio mais eficaz à sua liberdade de ação se soubessem que seus atos poderiam ser julgados não somente pela justiça americana, mas também por uma corte internacional imparcial onde posição hierárquica e privilégios institucionais são irrelevantes.

Se pudesse operar plenamente, o TPI certamente exerceria com maior eficácia as tarefas para as quais foi concebido. É portanto lamentável a campanha americana contra o Tribunal, que sem dúvida mina suas possibilidades de ação e sua credibilidade em nível global.

É certo que nenhum Estado gostaria de ver seus nacionais sendo julgados pela prática dos crimes mais odiosos para a humanidade. É sem dúvida uma situação no mínimo embaraçosa. Mas a busca de um mundo melhor fez com que tal embaraço fosse deixado de lado em prol de um ideal 
superior de justiça. Esperamos que um dia os Estados Unidos possam compartilhar deste ideal.

Revista Brasileira de Direito Internacional, Curitiba, v.1, n.1, jan./jun.2005 


\section{REFERÊNCIAS}

BENZING, Marcus. U.S. Bilateral Non-Surrender Agreements and Article 98 of the Statute of the International Criminal Court: An Exercise in the Law of

Treaties. Max Planck Yearbook of United Nations Law, vol. 8, p. 181-236, 2004.

BOUQUEMONT, Clémence. La Cour pénale internationale et les États-Unis. Paris: L'Harmattan, 2003.

BRASIL. Decreto 4.388, de 25 de setembro de 2002. Promulga o Estatuto de Roma do Tribunal Penal Internacional. Disponível em: www.planalto.gov.br.

Acesso em 23 mai. 2006.

CLAIRE, Trean. Une interprétation abusive de l'article 98 du traité de Rome, Le Monde, 4 de setembro de 2002, p. 02.

Countries Opposed to Signing a US Bilateral Immunity Agreement (BIA): US Aid Lost in FY04 and US Aid Threatened in FY05. Disponível no site www.iccnow.org. Acesso em 24 mai. 2006.

DENIS, Catherine. Le pouvoir normatif du Conseil de sécurité des Nations Unies: portée et limites. Bruxelles: Bruylant, 2004.

EUBANY, Cosmos. Justice for Some? U.S. Efforts Under Article 98 to Escape the Jurisdiction of the International Criminal Court. Hastings International and Comparative Law Review, vol. 27, n. 1, p. 103-129, 2003.

La torture dans la guerre. Le Monde, 9-10 mai. 2004.

MERCOSUL. Declaración Presidencial sobre Compromiso del Mercosur con el Estatuto de Roma de la Corte Penal Internacional, 20 de junho de 2005.

Disponível no site www.mercosur.int. Acesso em 24 mai. 2006.

PASTUJOVA, Kerstin. Was the United States justified in renewing Resolution 1487 in light of the Abu Ghraib prisoner abuse scandal?, ILSA Journal of International and Comparative Law, vol. 11, p. 195-216, 2004.

Status of US Bilateral Immunity Agreements (BIAs). Disponível no site www.iccnow.org. Acesso em 24 mai. 2006.

Revista Brasileira de Direito Internacional, Curitiba, v.1, n.1, jan./jun.2005 